\title{
Measures to Strengthen the Role of Primary Care Nurses During the COVID-19 Pandemic: A Concept Analysis
}

\author{
Aigerim Mukhamedyarova ${ }^{1}$, Tolebay Rakhypbekov ${ }^{2}$ (D), Marzhan Dauletyarova ${ }^{3}$ iD, Dinara Zhunussova ${ }^{4}$ (D), Oxana \\ Tsigengagel $^{5 *}$ (iD) Zaituna Khismetova ${ }^{6}$ (D) \\ ${ }^{1}$ Department of Medical Law and Ethics, NJSC "Astana Medical University", Nur-Sultan, Kazakhstan; ${ }^{2}$ National Association \\ Primary Health Care, Nur-Sultan, Kazakhstan; ${ }^{3}$ NJSC "Astana Medical University", Nur-Sultan, Kazakhstan; ${ }^{4}$ Department \\ of General Medical Practice and Evidence, NJSC "Astana Medical University", Nur-Sultan, Kazakhstan; ${ }^{5}$ Department of \\ Epidemiology and Biostatistics, NCJSC "Semey Medical University", Semey, Kazakhstan; ${ }^{6}$ Department of Public Health, NJSC \\ "Semey Medical University", Semey, Kazakhstan
}

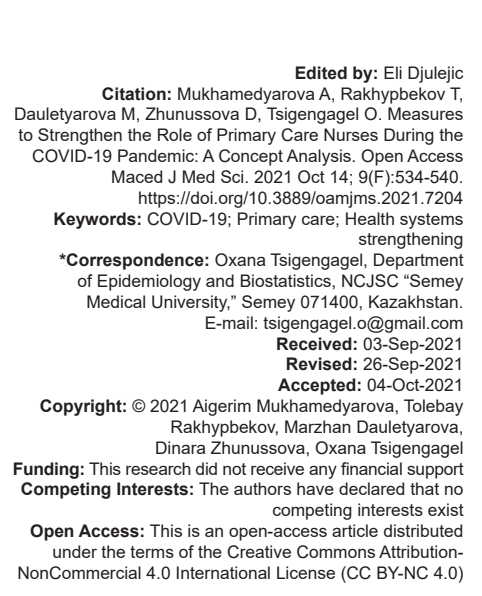

Abstract

The difficult epidemiological situation of COVID-19 infection in the world and in the country requires drastic measures to strengthen the material, technical, and staffing of primary healthcare (PHC). Under these circumstances, the preparedness of $\mathrm{PHC}$ systems in providing safe patient-centered care and meeting the current health needs of the population while preventing further transmission infection is crucial. Nurses play a crucial role in this process. This article reviews and summarize latest findings of explore the role of primary care nurses and their support measures in response to COVID-19 and to identify challenges to achieving universal health coverage. The study revealed that there is vast panoply of strategic reforms. There are a number of differences and similarities such as mandatory political commitment and leadership, governance and policy, funding and allocation of resources, and engagement of communities and role of other stakeholders.

\section{Introduction}

The 2018 Astana Declaration on Primary Health Care (PHC) positions $\mathrm{PHC}$ as the cornerstone of sustainable health systems, underpinning the achievement of universal health coverage and the health-related Sustainable Development Goals (SDGs) [1]. The three main components of $\mathrm{PHC}$ are as follows: (1) Primary care (as distinct from PHC, "primary care" is understood as "a key process in the health system that supports first-contact, accessible, continued, comprehensive, and coordinated patient-focused care" [1], and essential public health functions as the core of integrated health services; (2) multisectorial policy and action; and (3) empowered people and communities (Figure 1) [2]. These components frame key priority areas of interest for the international policymaking community in the context of COVID-19, which include scaling up and managing critical emergency services, continuing essential services, managing referral systems, engaging, and communicating with communities effectively, broader health determinants, and working multisectorally.
International health emergencies such as pandemics, including COVID-19, are reminders of the importance of PHC as a foundation for not only routine essential services but also health system emergency responsiveness [3]. COVID-19 has created a window of opportunity to revisit the role of $\mathrm{PHC}$ nurses, and more specifically, the multi-faceted health system issues that continue to challenge $\mathrm{PHC}$ "implementation" and therefore full realization of the Astana Declaration in many countries [4]. Drawing on the main components of $\mathrm{PHC}$ as defined in the Astana Framework and adopted in the WHO's "Operational framework for PHC: Transforming vision into action" [5], the review identifies the key enablers of, and barriers to, implementation of (1) primary care and essential public health functions as the central elements of integrated health services; (2) multi-sectorial policy and action; and (3) empowered people and communities. In addition, the review identifies emerging experiences and lessons from the COVID-19 pandemic relating to PHC nurses. Highly skilled nurses constitute the largest group of health professionals in $\mathrm{PHC}$, usually 
employed on a full- or part-time basis to provide clinical care and delivery of a range of programs designed to meet community needs [6]. Drawing from the analysis of impacts, enablers, barriers and gaps relevant to $\mathrm{PHC}$ implementation and with reference to the COVID-19 context, the review offers a comprehensive agenda for future PHC nurses-related research.

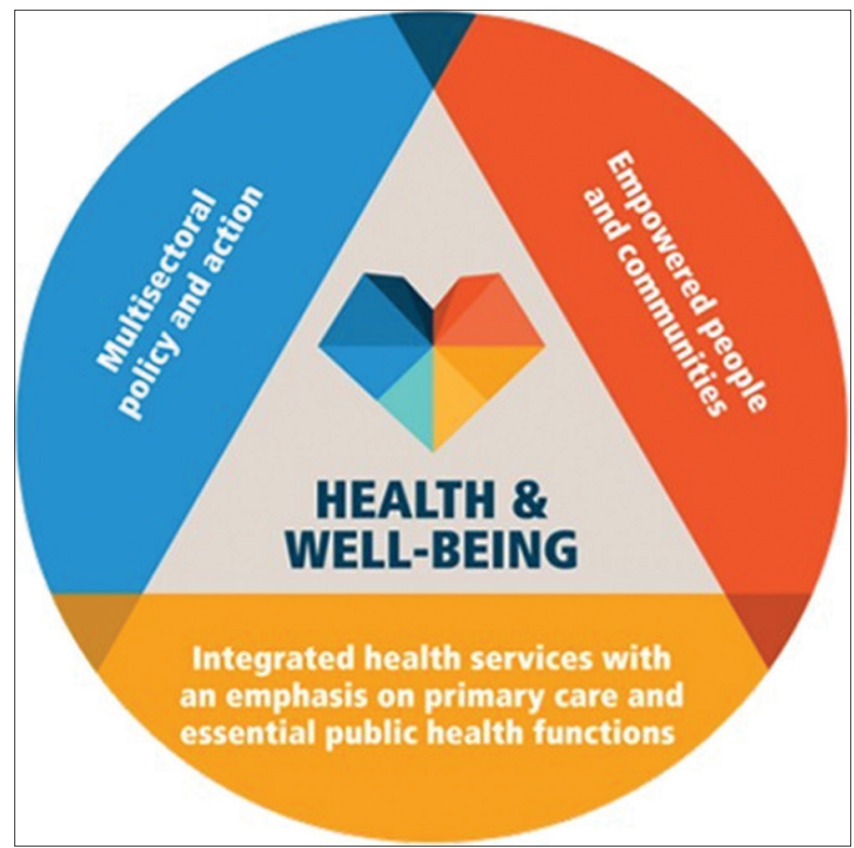

Figure 1: The World Health Organization's three main components of primary health care

The review findings identify the health systems strengthening strategies that should be prioritized to promote high-quality, equitable, people-centered PHC and to improve future responses to public health crises in the post-COVID-19 era.

\section{Materials and Methods}

A scoping review design was adopted to summarize the evidence from a diverse body of literature relevant to $\mathrm{PHC}$ impacts, enablers, and barriers. A MEDLINE and PubMed search were performed for the key words "PHC" or "primary care" or "PHC" AND "COVID-19" in the title or abstract. This approach enabled the review to leverage the substantial body of synthesis work produced within the recent decade (2010-2021) and to concentrate the review on common issues and challenges relating to PHC impacts and implementation across countries. Included papers were peer-reviewed publications and literature published in English, with papers published before 2010 excluded to maximize the policy relevance of the findings while ensuring adequate breadth. Following duplicate removal, title-abstract records were scanned and excluded if they clearly did not meet the inclusion criteria. Eligibility assessment was performed independently in an unblinded standardized manner by two reviewers. Disagreements between reviewers were resolved by consensus. Collected data were used for the final analysis, whose endpoints were to evaluate the small number of non-empirical policy analyses and commentaries were included through this process because of their direct examination of $\mathrm{PHC}$ implementation enablers and barriers. The flowchart for criteria and inclusion is presented in Figure 2.

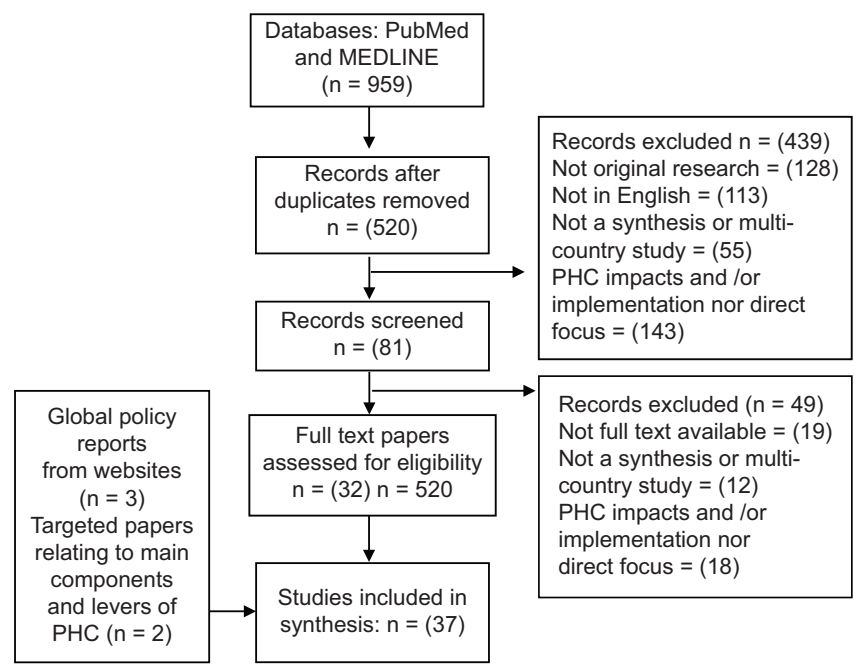

Figure 2: Flow diagram of the study selection

\section{Results}

In total, 81 papers were included in the review following screening and eligibility assessment and 37 were identified through of the searching and selection process (Figure 2). Of the 37, 15 were various literature reviews (e.g., systematic review, scoping review and rapid evidence synthesis), five were literature reviews combined with empirical studies, five were empirical studies (without a literature review component), and seven were global policy reports incorporating evidence syntheses. A further five papers were non-empirical commentaries, conceptual analyses or descriptions of programs. The additional five targeted papers identified and added were predominantly literature reviews and policy analyses that addressed specific aspects of the three main components of $\mathrm{PHC}$ and that had a global or low- and middle-income country (LMIC) focus. Table 1 shows the countries and regions that were the focus of these 37 papers

\section{Discussion}

This review provides a timely synthesis, given the importance of $\mathrm{PHC}$ in the ongoing COVID-19 
pandemic response, of the literature on $\mathrm{PHC}$ impacts and implementation enablers and barriers with reference to the three main components of $\mathrm{PHC}$ [2]. The review demonstrates that a strong, diverse civil society represented at all levels in cross-sectorial governance arrangements and PHC-oriented health systems underpinned by political commitment to sustaining PHC implementation and equity-informed financing and workforce models are central enablers in advancing PHC. Emerging lessons from COVID-19 responses similarly highlight the importance of community co-production of health and people-centered, participatory forms of community engagement [7], [13].

Table 1: Reported countries or regions of focus in papers identified in the review

\begin{tabular}{|c|c|c|}
\hline $\begin{array}{l}\text { Countries/region } \\
\text { of focus }\end{array}$ & $\begin{array}{l}\text { Number of } \\
\text { papers }(n=37)\end{array}$ & References \\
\hline Global & 9 & $\begin{array}{l}\text { WHO and UNICEF (2018), } \\
\text { WHO (2020b), United National General Assembly } \\
\text { (2019), WHO (2015). Ghebreyesus, Tedros } \\
\text { Adhanom. (2020), PUnited National General } \\
\text { Assembly (2019), State of commitment to universal } \\
\text { health coverage: synthesis, (2020), OECD (2021), } \\
\text { Global Nursing and Health Expert Panel (2018) }\end{array}$ \\
\hline Asia Pacific region & 10 & $\begin{array}{l}\text { Halcomb et al. (2014), Guzys et al. (2017), } \\
\text { Halcomb et al. (2020), Seale et al. (2012), } \\
\text { Fernandez et al. (2020), Halcomb et al. (2018), } \\
\text { Khalid et al. (2016), Desborough et.al (2021), } \\
\text { Bazargani et al. (2020), Angell et al. (2019) }\end{array}$ \\
\hline European region & 5 & $\begin{array}{l}\text { Yoshida (2016), Marston et al. (2020); Jordan et al. } \\
\text { (2020), Verbeek et al. (2020), Duncan et al. (2020) }\end{array}$ \\
\hline $\begin{array}{l}\text { East and Southern } \\
\text { Africa }\end{array}$ & 2 & Loewenson et al. (2020a), Jenkins et al. (2020) \\
\hline $\begin{array}{l}\text { United States of } \\
\text { America }\end{array}$ & 7 & $\begin{array}{l}\text { Nicholas et al. (2021), Livingston et al. (2020), } \\
\text { Ehrlich et al. (2020), Hader et al. (2013); Shah et.al } \\
\text { (2020), Ballard et al. (2020), Bitton et al. (2019) }\end{array}$ \\
\hline $\begin{array}{l}\text { Southeast and } \\
\text { East Asia }\end{array}$ & 4 & $\begin{array}{l}\text { Du et al. (2019), Basu et al. (2020), Bhaumik et al. } \\
\text { (2020), Suandika et al. (2021) }\end{array}$ \\
\hline
\end{tabular}

\section{Perspective from LMICs}

$\mathrm{PHC}$ research has advanced predominantly in high-income countries (HICs) [7], [8]. Many LMICs are still establishing family medicine as a specialty, and despite global declarations, $\mathrm{PHC}$ receives variable and often fleeting attention from government leaders and is grossly underfunded in most LMICs; furthermore, there is a lack of accountability mechanisms to maximize population-level health outcomes and social participation in health system governance and service delivery functions [9].

Despite the primacy of the strategic levers, we found that many successful reform strategies required these to be combined with a wide range of operational levers. The most mature evidence relates to workforce strengthening initiatives. Adequately motivated, digitally enabled, supportively supervised PHC teams with ample autonomy and decision space, and clearly delineated and complementary tasks, can improve service access, coverage and quality while also improving workforce satisfaction and retention. Professionalization of and continuing support for the community health workforce is a core priority [10].

Investment in strategies that embrace the complex leadership roles of highly trained primary care professionals such as doctors and nurses is also needed, such that management and clinical skills are equally valued [11]. Strategies to effectively regulate and engage with private sector health professionals are also critically important, given that they are the first point of contact in many countries. This again highlights the importance of strategic levers (regulation) being combined with operational levers (workforce engagement and strengthening).

Thus, the COVID-19 pandemic accelerates transformation of health systems, and stimulates many innovative $\mathrm{PHC}$ systems. Promoting the wider adoption and sustainability of these innovations will require both technical leadership and managerial support to enable legislation and regulation, and introduce the right incentives to accelerate change. Measurement, benchmarking, sharing good practice examples and lessons learnt from COVID-19 will provide the basis for building blocks of resilient health care systems [12].

\section{Impact of COVID-19 on nursing care processes and care delivery}

Any pandemic has a significant impact on health systems, particularly the workforce [13], [14]. Nurses constitute the largest professional group within health care globally and, as such, are a pivotal component of coordinated responses to such events [15]. Historically, nurses have always played a role in infection prevention and control, and in caring for people during crises [16]. The COVID-19 pandemic has been no exception. Nurses have played a key role in working to identify, isolate and manage those with COVID-19 and in supporting those who have non-COVID-19 related health needs [17]. PHC nurses work in a range of diverse settings including general (family) practice, community nursing services, schools, residential care settings, non-governmental organizations and workplaces [18]. These nurses provide a range of vital nursing services to promote and maintain health within the community across the lifespan [19].

The rapid emergence of COVID-19 has had wide-ranging effects on nurses' ability to deliver patient care. The effects of the pandemic on decisionmaking reported by experienced nurses ranged from the individual or intrapersonal factors (e.g., maintaining awareness for rapidly changing patient status), the interpersonal level (e.g., the inability to gather information from patient families), and to the systems level (e.g., availability of personal protective equipment [PPE] to facilitate direct contact with patients). Findings are summarized as a work system model (Figure 3) by adapting the Systems Engineering Initiative for Patient Safety model. The original model posits that multiple work-system elements (i.e., people, environment, tasks, technology/tools, and organizational factors) interact and influence healthcare processes [20]. 


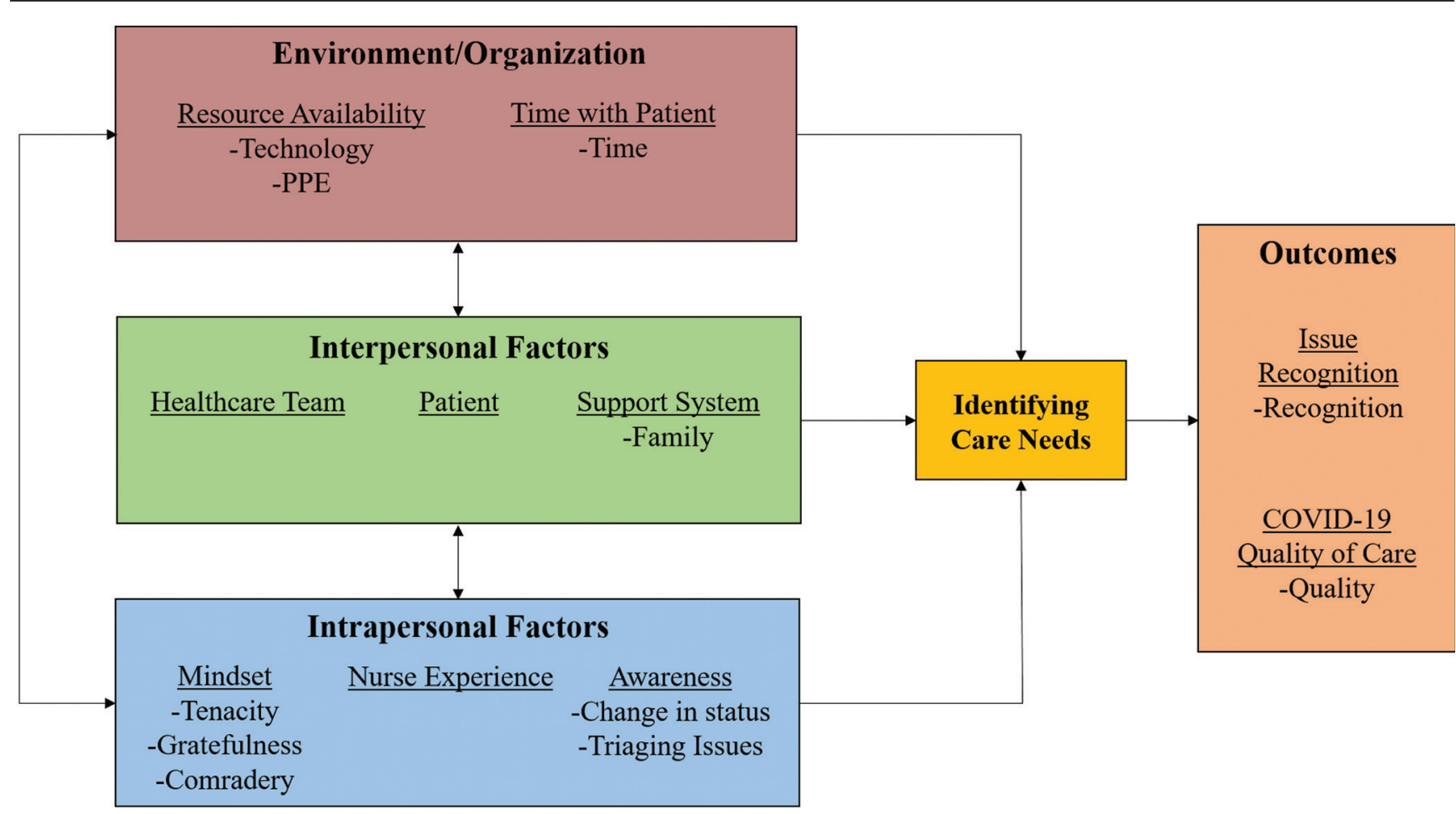

Figure 3: Identifying factors that nurses consider in the decision-making process related to patient care during the COVID-19 pandemic

Most studies have highlighted a lack of PPE as the major concern for participants. In the context of COVID-19, a worldwide shortage of PPE, as a result of insufficient stockpiles and disrupted supply chains, saw health care professionals exposed to infection [21]. Significant number of healthcare workers dying globally due to COVID-19 exposure [22] highlights the need for more to be done internationally to ensure that sufficient PPE is available to protect health-care professionals during future pandemics. In addition to addressing supply issues, clearly communicated and evidencebased principles around recommended PPE use will ensure the prudent use of available supplies [23].

COVID-19 has tested international healthcare systems in a way not seen before in our lifetime. The previous studies have found that while participants experienced positive aspects around information sharing and communication, improvements in the delivery of messages, community and health professional education and clearer information about COVID-19 (including management protocols and up-todate information) could support them to better deliver quality care. According to the reviews of the pandemic experiences of acute care nurses [24], reported that nurses wanted to ensure that they had the appropriate education to provide care and felt that rapidly changing information increased their stress levels. Enhancing systems and processes for communication across the health system during crises is particularly important in PHC given the large numbers of individual health providers involved in the delivery of care.

Most universal health-care systems are funded through the national health insurance scheme, the provision and funding of $\mathrm{PHC}$ is complex. $\mathrm{PHC}$ services are delivered by a combination of non-government organizations, state/territory-funded community health services, and small business and corporate chain general practices. This multitude of service providers and variations in the funding of services can impact the ability of the sector to effectively implement new models of service delivery. This creates complexity as the funding received for the delivery of nursing services is variable depending on the specific scheme that funds that service. Such variation has a flow-on effect to create challenges in the consistency of remuneration and work conditions for nurses [25]. The issues raised by this study, and throughout COVID-19, highlight the urgent need to address funding and industrial concerns around $\mathrm{PHC}$ nursing to ensure that these nurses have job security and are retained in PHC employment.

Most studies have identified concern for participants own mental health and well-being during and following the pandemic. The psychological impact of pandemics on acute care nurses has been previously identified [26]. Many nurses have a strong sense of professional obligation to provide nursing care during a pandemic. However, the uncertainty of the situation, extreme pressures of high workload demands and need to prioritize resources have been reported to create feelings of vulnerability, loneliness, powerlessness, and both physical and psychological exhaustion [27]. The impact of the nursing role is also overlaid with the psychological impacts facing all members of the community in terms of fear of contracting the pathogen, concerns for family and the impacts of social isolation [28]. Ensuring that nurses and other health professionals are 
well supported to maintain their mental health during times of crises is an important strategy to ensure that the workforce remains available to provide health-care services to the community during and beyond the crisis.

Participants' experiences of the COVID-19 pandemic raised the issue of PHC nurses not feeling valued or recognized for their role. Perceptions of a lack of respect for nurses and a lack of a voice and autonomy are cited as key factors leading to nurses leaving the profession. Conversely, recognizing the efforts of nurses attracts nurses to work during future crises [29]. Despite significant advances in the professionalization of nursing, these study findings demonstrate that the male-dominated medical profession is valued ahead of the female-dominated nursing profession [30]. Communicating the value of $\mathrm{PHC}$ nursing in providing care is an ongoing issue in the sector, where more could be done to promote the role within the $\mathrm{PHC}$ team and the community and as contributors to health policy [25]. This highlights the need for professional nursing organizations to take an active role to advocate on behalf of the profession and ensure that the voice of nurses is valued within the healthcare and health policy sphere across both acute and PHC.

\section{Framework for advancing improvement in primary care nurses}

Beyond primary care, COVID-19 brought relevant lessons for health policy and health systems at large. In the context of this analysis we identified five points (Figure 4). The first is the need to come to a full understanding of importance of primary care in responding to a pandemic and value its power to swiftly adapt to circumstances it had never before experienced while maintaining a strong rapport with local practice populations. A system of primary care performance measurement that meets the information needs of the public, governments and ministries of health, regional health authorities, local communities and primary care practices and organizations for the purposes of public reporting, accountability, planning, and quality improvement. Health IT that effectively supports patients and providers through decision support tools for clinicians and patients, support for patient selfmanagement, performance measurement and reporting capacity and interconnectivity for information exchange across health-care settings [31].

The second is the creation and ongoing support of primary care organizations or governance mechanisms at the local, regional, and provincial/ territorial levels that give primary care providers a collective voice and enable them to assume collective responsibility for addressing population health needs, to engage effectively with other healthcare sectors and, at the local or regional level, to promote, coordinate and support quality improvement activities and share resources, and importance to support professionals in primary care to cope with the stress and strains of working under conditions of a pandemic, through balanced work scheduling and collaborative working relationship in defined geographical areas. Efforts to improve quality and safety need to be focused to systematic evaluation of primary care services and policy innovation to allow shortcomings to be identified and addressed and successes to be reinforced and sprea [32].

As a third, it is essential to protect primary care services and to make sure that such services are provided to all those who need it. Funding and provider payment arrangements that are aligned with quality goals, including blended payment arrangements, mechanisms to support coordination and integration, which could include mandatory requirements for the content and timeliness of communication at care transition points and funding mechanisms that span care sectors such as bundled payments for episodes of care or multi-sector capitation covering the general population; given the uncertainty about feasibility and impact, payment innovations need to be tested on a small scale before system-wide adoption. Adequate funding of primary care research and research training to supply evidence to inform policy, management, and practice [33].

The fourth point is that the COVID-19 experience stresses the importance of interaction between primary care and public health. Patient enrolment with primary care providers and organizations; this provides a foundation for a proactive, population based approach to preventive care and chronic disease management and for systematic practice-level performance measurement and quality improvement [33], [34].

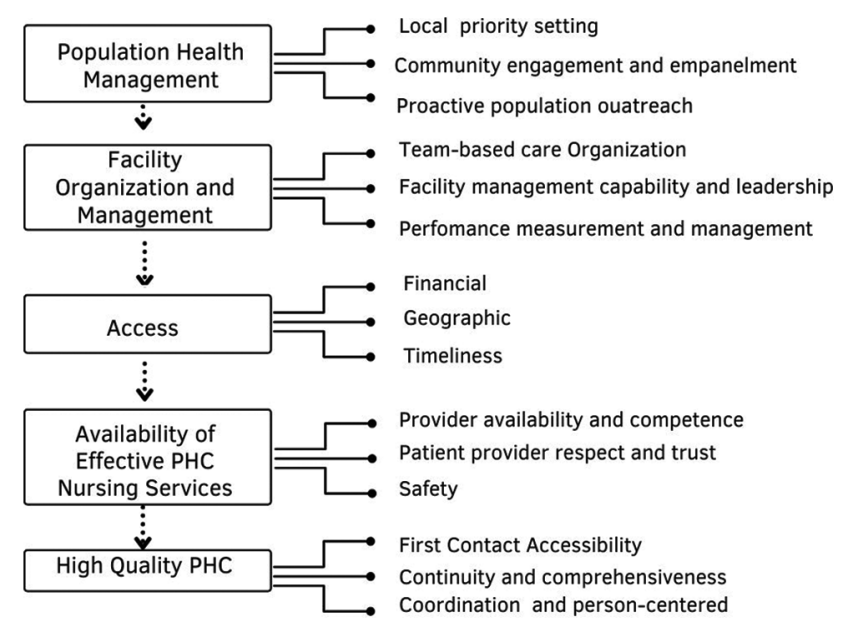

Figure 4: The concept analysis of strengthen in Primary Care Nurses

The fifth point is that the experiences collected during the COVID-19 pandemic should find their way into the teaching and training of health professionals. As COVID-19 had an impact on health systems in all their components, this makes it particularly attractive to address professional needs through multidisciplinary teaching and training programs - involving public health, primary and 
hospital care, from nurses, physicians to allied health professionals together. Responding to pandemics requires international collaborations, thus it would be appropriate that teaching and training programs could also operate in an international context [35], [36], [37].

\section{Conclusion}

COVID-19 has revealed gross deficiencies in health systems around the world, mainly in LMICs highlighting the need for transformational change, at the center of which should be the strengthening of PHC. This secondary analysis of literature reviews, EGMs and recent literature informed by experts in the field synthesizes what was already known about best practices to strengthen PHC before COVID-19. Findings from this study indicate that the COVID-19 pandemic has significantly impacted on the job security, workload, service provision, support requirements and safety concerns for nurses working in PHC. Improving the health of populations and enhancing the experience of receiving care in a sustainable way requires changes in the way that primary care is organized and delivered. These factors also have the potential to affect quality of care provided and morbidity rates within communities. This paper provides nurse leaders, employers, and policymakers with $\mathrm{PHC}$ based evidence to effectively plan and optimize the allocation of nursing resources in line with organizational goals during the current and future pandemics. Achieving this on a broad scale will require a supportive health system environment and the use of proven quality improvement methods and supports such as external coaches as well as policies and structures at a system-wide level to reinforce and make possible the changes required.

\section{References}

1. World Health Organization and United Nations Children's Fund. A Vision for Primary Health Care in the $21^{\text {st }}$ Century: Towards Universal Health Coverage and the Sustainable Development Goals. Geneva: World Health Organization and the United Nations Children's Fund; 2018.

2. World Health Organization and United Nations Children's Fund. Operational Framework for Primary Health Care: Transforming Vision into Action. Geneva: World Health Organization and the United Nations Children's Fund; 2020.

3. World Health Organization. Role of Primary Care in the COVID19 Response: Interim Guidance. Geneva: World Health Organization, Western Pacific Region; 2020. Available form: https://www.apps.who.int/iris/bitstream/handle/10665/331921/ Primary-care-COVID-19-eng. pdf? sequence=1\&isAllowed=y. [Last accessed on 2021 Aug 30].

4. Ghebreyesus TA. Strengthening our resolve for primary health care. Bull World Health Organ. 2020;98(11):726A. https://doi. org/10.2471/BLT.20.279489

PMid:33177764

5. United National General Assembly. Political Declaration of the High-level Meeting on University Health Coverage. Geneva: United National General Assembly; 2019. Available from: http:// www.un.org/pga/73/wp-content/uploads/sites/53/2019/07/ FINAL-draft-UHC-Political-Declaration.pdf. [Last accessed on 2021 Aug 25].

6. Halcomb EJ, Salamonson $\mathrm{Y}$, Davidson PM, Kaur $\mathrm{R}$, Young SA. The evolution of nursing in Australian general practice: A comparative analysis of workforce surveys ten years on. BMC Family Pract. 2014;15:52. https://doi. org/10.1186/1471-2296-15-52

PMid:24666420

7. Loewenson R, Colvin C, Rome N, Nolan E, Coelho VS, Szabzon $\mathrm{F}$, et al. We are subjects, not objects in Health: Communities Taking Action on COVID-19. Zimbabwe: Training and Research Support Centre in the Regional Network for Equity in Health in East and Southern Africa (EQUINET) and Shaping Health; 2020a.

8. Yoshida S. Approaches, tools and methods used for setting priorities in health research in the $21^{\text {st }}$ century. J Glob Health. 2016;6(1):010507. https://doi.org/10.7189/jogh.06.010507 PMid:26401271

9. State of Commitment to Universal Health Coverage: Synthesis, 2020. UHC2030; 2020. Available form: https://www.uhc2030. org/fileadmin/uploads/uhc2030/Documents/Key_Issues/ State_of_UHC/SoUHCC_synthesis_2020_final_web.pdf. [Last accessed on 2020 Dec 24].

10. Bhaumik S, Moola S, Tyagi J, Nambiar D, Kakoti M. Community health workers for pandemic response: A rapid evidence synthesis. BMJ Glob Health. 2020;5(6):e002769. https://doi. org/10.1136/bmjgh-2020-002769 PMid:32522738

11. Jenkins LS, Von Pressentin KB, Naidoo K, Schaefer R. The evolving role of family physicians during the coronavirus disease 2019 crisis: An appreciative reflection. Afr J Prim Health Care Fam Med. 2020;12(1):e1-4. https://doi.org/10.4102/phcfm. v12i1.2478 PMid:32634002

12. Available from: https://www.oecd.org/coronavirus/ policy-responses/strengthening-the-frontline-howprimary-health-care-helps-health-systems-adapt-during-thecovid-19-pandemic-9a5ae6da. [Last accessed on 2021 Aug 14].

13. Marston C, Renedo A, Miles S. Community participation is crucial in a pandemic. Lancet. 2020;395(10238):1676-8. https:// doi.org/10.1016/S0140-6736(20)31054-0

PMid:32380042

14. Seale H, Wang Q, Yang P, Dwyer D, Zhang Y, Wang X, et al. Hospital health care workers understanding of and attitudes toward pandemic influenza in Beijing. Asia Pac J Public Health. 2012;24(1):39-47. http://dx.doi.org/10.1177/1010539510365097 PMid:20460279

15. Jordan RE, Adab P, Cheng KK. Covid-19: Risk factors for severe disease and death. BMJ. 2020;368:m1198. https://doi. org/10.1136/bmj.m1198

16. Corless IB, Nardi D, Milstead JA, Larson E, Nokes KM, Orsega $\mathrm{S}$, et al. Expanding nursing's role in responding to global pandemics 5/14/2018. Nurs Outlook. 2018;66(4):412-5. https://doi.org/10.1016/j.outlook.2018.06.003 PMid:30031544

17. Halcomb E, McInnes S, Williams A, Ashley C, James S, Fernandez $\mathrm{R}$, et al. The experiences of primary health care nurses during the COVID-19 pandemic in Australia. J Nurs 


Scholarsh. 2020;52(5):553-63. https://doi.org/10.1111/
jnu.12589
PMid:32735758

18. Guzys D, Whitehead D, Brown R, Halcomb EJ. An Introduction to Community and Primary Health Care. $2^{\text {nd }}$ ed. Melbourne, VIC, Australia: Cambridge University Press; 2017.

19. Suandika M, Tang WR, Ulfah M, Cahyaningrum ED. Selfconfidence of nurses philosophy: A concept analysis. Open Access Maced J Med Sci. 2021;9(4):206-11.

20. Anton N, Hornbeck T, Modlin S, Haque MM, Crites M, Yu D. Identifying factors that nurses consider in the decision-making process related to patient care during the COVID-19 pandemic. PLoS One. 2021;16(7):e0254077. https://doi.org/10.1371/ journal.pone. 0254077

PMid:34214122

21. Livingston $E$, Desai $A$, Berkwits $M$. Sourcing personal protective equipment during the COVID-19 pandemic. J Am Med Assoc. 2020;323(19):1912. https://doi.org/10.1001/jama.2020.5317 PMid:32221579

22. Ehrlich $\mathrm{H}$, McKenney M, Elkbuli A. Protecting our healthcare workers during the COVID-19 pandemic. Am J Emerg Med 2020;38(7):1527-8. https://doi.org/10.1016/j.ajem.2020.04.024 PMid:32336585

23. Verbeek JH, Rajamaki B, ljaz S, Sauni R, Toomey E, Blackwood B, et al. Personal protective equipment for preventing highly infectious diseases due to exposure to contaminated body fluids in healthcare staff. Cochrane Database Syst Rev. 2020;4(4):CD011621. https://doi.org/10.1002/14651858. CD011621.pub4

PMid:32293717

24. Fernandez R, Lord H, Halcomb EJ, Moxham L, Middleton R, Alananzeh I, et al. Implications for COVID-19: Asystematic review of nurses' experiences of working in acute care hospital settings during a respiratory pandemic. Int J Nurs Stud. 2020;111:103637. https://doi.org/10.1016/j.ijnurstu.2020.103637 PMid:32919358

25. Halcomb E, Ashley C, James S, Smyth E. Employment conditions of Australian primary health care nurses. Collegian. 2018;25(1):65-71. https://doi.org/10.1016/j.colegn.2017.03.008

26. Hader $\mathrm{R}, \mathrm{Ne}-\mathrm{Bc} \mathrm{R}$, Officer $\mathrm{C}$. The power of appreciation. Nurs Manage. 2013;44(3):6. https://doi.org/10.1097/01. NUMA.0000427187.49930.77 PMid:23392284

27. Du S, Cao Y, Zhou T, Setiawan A, Thandar M, Koy V, et al. The knowledge, ability, and skills of primary health care providers in SEANERN countries: A multi-national cross-sectional study. BMC Health Serv Res. 2019;19(1):602. https://doi.org/10.1186/ s12913-019-4402-9
28. Shah K, Kamrai D, Mekala H, Mann B, Desai K, Patel RS Focus on mental health during the coronavirus (COVID-19) pandemic: Applying learnings from the past outbreaks. Cureus. 2020;12(3):e7405.

PMid:32337131

29. Khalid I, Khalid TJ, Qabajah MR, Barnard AG, Qushmaq IA Healthcare workers emotions, perceived stressors and coping strategies during a MERS-CoV Outbreak. Clin Med Res. 2016;14(1):7-14. https://doi.org/10.3121/cmr.2016.1303 PMid:26847480

30. Duncan DL. What the COVID-19 pandemic tells us about the need to develop resilience in the nursing workforce. Nurs Manage. 2020;27(3):22-7. https://doi.org/10.7748/nm.2020. e1933

PMid:32400142

31. Desborough J, Dykgraaf SH, Phillips C, Wright M, Maddox R, Davis $S$, et al. Lessons for the global primary care response to COVID-19: A rapid review of evidence from past epidemics. Fam Pract. 2021;2021:cmaa142. https://doi.org/10.1093/ fampra/cmaa142

PMid:33586769

32. Ballard M, Bancroft E, Nesbit J, Johnson A, Holeman I, Foth J, et al. Prioritising the role of community health workers in the COVID-19 response. BMJ Global Health. 2020;5(6):e002550. http://doi.org/10.1136/bmjgh-2020-002550

PMid:32503889

33. Sadeghi Bazargani H, Saadati M, Tabrizi JS, Farahbakhsh M, Golestani M. Forty years after Alma-Ata: How people trust primary health care? BMC Public Health. 2020;20(1):942 https://doi.org/10.1186/s12889-020-09082-w PMid:32539779

34. World Health Organization. WHO Global Strategy on Peoplecentred and Integrated Health Services: Interim Report. Geneva, Switzerland: World Health Organization; 2015.

35. Bitton A, Fifield J, Ratcliffe $\mathrm{H}$, Karlage A, Wang $\mathrm{H}$, Veillard JH, et al. Primary healthcare system performance in low-income and middle- income countries: A scoping review of the evidence from 2010 to 2017. BMJ Glob Health. 2019;4(8):e001551. https://doi. org/10.1136/bmjgh-2019-001551

36. Angell B, Dodd R, Palagyi A, Gadsden T, Abimbola S, Prinja S, et al. Primary health care financing interventions: A systematic review and stakeholder-driven research agenda for the AsiaPacific region. BMJ Glob Health. 2019;4(8):e001481. https:// doi. org/10.1136/bmjgh-2019-001481

37. Basu S. Non-communicable disease management in vulnerable patients during Covid-19. Indian J Med Ethics. 2020;5(2):103-5. https://doi. org/10.20529/IJME.2020.041 PMid:32393447 